\title{
OPEN Effect of polyaniline content and protonating dopants on electroconductive composites
}

\author{
Katarzyna Bednarczyk ${ }^{1}$, Wiktor Matysiak ${ }^{2}$, Tomasz Tański², Henryk Janeczek ${ }^{3}$, \\ Ewa Schab-Balcerzak ${ }^{1,3}$ \& Marcin Libera ${ }^{1 \bowtie}$
}

Elastic constructive elements prepared by electrospinning using polyacrylonitrile/polyaniline (PAN/ PANI) electroconductive composites were prepared and investigated in terms of their thermal and mechanical properties. This study was focused on the impact of the type of counterion of polyaniline and the PANI content in composites on the thermal, conductive and morphological properties of electrospun fibers. In this study, composites obtained from PANI doped with sulfuric acid showed the highest conductivity, and composites obtained from PANI doped with hydrochloric acid showed the highest thermal stability. All obtained composites exhibited good thermal stability, with $\mathrm{T}_{5}$ values in the range of $230-268^{\circ} \mathrm{C}$ that increased with increasing PANI content. The prepared composites exhibited comparable PAN $\mathrm{T}_{g}$ values, which indicates their suitability for processing. Instrumental analysis of polymers and composites was carried out using UV-visible spectroscopy, thermogravimetric analysis, differential scanning calorimetry, dynamic mechanical thermal analysis and scanning electron microscopy.

Electroconductive composites of polymers that can be processed by electrospinning to form elastic constructive materials are of major scientific and research interest for their application in innovative detectors, cells or diodes $^{1,2}$. Conductive composites, due to their ability to be used as a building material, can be applied in electronic devices, such as batteries, capacitors, and photovoltaic cells. Assembly by electrospinning using conductive composites allows the production of elements for the construction of photonic devices, among others ${ }^{3,4}$.

Photovoltaics are one of the many areas of application for PANI nanofibers because this polymer is an attractive alternative to the platinum counter electrode for dye-sensitized solar cells (DSSCs) due to its lower cost of production. To date, many DSSCs in which the counter electrode was made of PANI or was supplemented with this polymer in nanoparticle form have been investigated, and the efficiencies of cells based on this type of material vary depending on the PANI form and admixture concentration (from 0.68 to $7.15 \%)^{5-11}$.

Polyaniline has been one of the most investigated conductive polymers in recent years due to its unsophisticated synthesis and good thermal stability ${ }^{12}$. Two major routes of PANI synthesis are chemical oxidative polymerization and electrochemical polymerization. The properties of polyaniline depend on the synthesis methodology and protonation state. The reduced form of polyaniline is leucoemeraldine, and the oxidized form is pernigraniline. The neutral form, which is half reduced and half oxidized, is emeraldine base. Proton-doped polyaniline, produced using acids, forms emeraldine salt, which is a highly conducting polymer ${ }^{13}$. The synthesis of emeraldine salt is most often accomplished by oxidative polymerization in acidic media ( $\mathrm{pH} \mathrm{1-3)} \mathrm{using}$ oxidants such as potassium dichromate and ammonium persulfate (APS) ${ }^{14}$.

The shape and size of polyaniline particles depend on the synthesis procedure. In the literature, a large variety of procedures are used to obtain a defined shape and size for polyaniline. PANI can be formed into particles, spheres, wires, tubes and fibers ${ }^{15,16}$. Among the different methods to generate PANI with specific morphologies, two main approaches can be distinguished based on the use of templates (hard-template, soft-template) or no templates in the syntheses ${ }^{15-17}$. The template-based method is associated with problematic removal of the template from the reaction and reduced conductivity of the obtained polymers ${ }^{17}$. Template-based synthesis usually provides PANI in the shape of rods and fibers, whereas template-free synthesis results in spheres. The shape of the polymerization product depends strongly on the $\mathrm{pH}$ of the solution. Nanotubes are produced in weakly acidic media ${ }^{18,19}$, while nanofibers are produced in alkaline media ${ }^{20}$. In oxidative polymerization, the shape depends

${ }^{1}$ Institute of Chemistry, University of Silesia in Katowice, 9 Szkolna Str., 40-006 Katowice, Poland. ${ }^{2}$ Institute of Engineering Materials and Biomaterials, Silesia University of Technology, 18A Konarskiego Str., 44-100 Gliwice, Poland. ${ }^{3}$ Centre of Polymer and Carbon Materials, Polish Academy of Sciences, 34 M. Curie-Sklodowskej Str., 41-819 Zabrze, Poland. ${ }^{\circledR}$ email: marcin.libera@us.edu.pl 


\begin{tabular}{|l|l|l|l|l|}
\hline Polymer & Aniline (g) & Ammonium persulfate (g) & Acid & Reaction yield (\%) \\
\hline PANI A & 9.313 & 28.523 & Hydrochloric acid (A) & 92 \\
\hline PANI B & 7.672 & 23.480 & Acetic acid (B) & 87 \\
\hline PANI C & 5.131 & 15.701 & Sulfuric acid (C) & 93 \\
\hline
\end{tabular}

Table 1. Amounts of reagents used in the synthesis of polyaniline.

on the molar ratio of acid to aniline (Ani). In the case of hydrochloric acid ( $\mathrm{HCl}$ ) applied in a 1:1 ratio to Ani, the products are most often spheres and fibers with an average length of $1.2 \mu \mathrm{m}$. A change in the molar ratio of $\mathrm{HCl}$ to Ani to 3:2 results in a polymer shaped as microsized flakes without any regular morphology. Meanwhile, the product of synthesis conducted with a 2:1 molar ratio of $\mathrm{HCl}$ to Ani were flakes and fibers with an average length of 250-300 $\mu \mathrm{m}$. Increasing the molar ratio to 4:1 produced fibers; these fibers can be $5 \mathrm{~cm}$ long when the molar ratio during synthesis is $8: 1$. The fiber diameter differs with the molar ratio of ammonium persulfate to Ani. With an increasing APS:Ani molar ratio, the size of the polymer decreases, and the shape changes from nanorods to nanoparticles ${ }^{21}$. The morphology of PANI particles also varies with the Ani concentration in the reaction mixture. Synthesis at a molar ratio of $1: 1$ and a lower $\left(4.910^{\star} 10^{-2} \mathrm{M}\right)$ concentration of Ani shows a larger average diameter and better ordered fibers for the product than a higher concentration $\left(7.810^{\star} 10^{-2} \mathrm{M}\right)^{22}$.

PANI has great application potential; however, due to its low solubility in ordinary organic solvents, its processing generates many problems. Accordingly, pure PANI nanofibers are rarely produced by electrospinning; instead, polyaniline is mixed with other polymers to produce a homogeneous spinning solution ${ }^{23,24}$. Such a procedure simplifies the electrospinning process and improves the mechanical properties of fibers ${ }^{25,26}$.

In 2009, Raeesi et al. presented a method of obtaining PAN/PANI nanofibers by electrospinning from a solution of PANI and PAN in N-methylpyrrolidone ${ }^{5}$. PANI that had been synthesized by oxidative polymerization in acidic medium was dissolved in NMP (N-metylo-2-pirolidon). A PAN mixture in NMP (20 wt $\%$ ) was added to a solution of PANI in various amounts. The solutions for electrospinning varied in PANI concentration (10-30 $\mathrm{wt} \%$ ). The processing resulted in fibers with diameters ranging from 60 to $600 \mathrm{~nm}$ depending on the PANI concentration. The fiber diameter decreased with increasing PANI concentration. The conductivity of the prepared fibers, as expected, increased with increasing PANI concentration in the mixture.

In 2014, Zhang et al. described a method of electrospinning PAN/PANI nanofibers using a solution of polymers in N,N-dimethylformamide ${ }^{6}$. A morphology analysis of PANI/PAN composite membranes carried out by SEM confirmed that the fibers were highly porous and that changing the voltage during the electrospinning had a significant effect on the diameter of the fibers produced. As the voltage was increased, an increase in diameter from 125 to $222 \mathrm{~nm}$ was observed, which was the result of more charges being generated on the surface of the solution and better stretching of the polymer. In 2014, PANI/PAN nanofibers were produced by an electrospinning dimethyl sulfoxide:PAN:PANI solution ${ }^{7}$. The PAN concentration was kept constant at $7 \%$ by weight, while the PANI concentration was 1, 3 or $5 \%$ by weight relative to the weight of the PAN. Analysis of the morphology of the obtained conductive nanomaterials showed that as the concentration of conductive polymer increased, the fiber diameter, conductivity and elongation of the sample increased.

As an alternative to conventional electrode materials, stretchable conductive nanocomposites composed of conducting nanomaterials and elastomeric media have been extensively studied for stretchable interconnections and devices. These stretchable conductive nanocomposites consist of percolation networks of nanoscale conductive fillers in elastomeric matrixes.

DMTA is widely used for material analysis, especially to determine the viscoelastic properties of polymers. When the temperature is continuously changed, the material is exposed to an oscillatory force. The mechanical properties of polymers, such as the storage modulus ( $\left.E^{\prime}\right)$ and the loss modulus ( $\left.E^{\prime \prime}\right)$, can be determined by dynamic mechanical thermal analysis (DMTA). The storage modulus represents the elastic properties, and the loss modulus represents the viscous properties of a material. The $\mathrm{E}^{\prime \prime}$ to $\mathrm{E}^{\prime}$ ratio is the loss factor (tangent $\delta$ ) and represents the damping properties of materials. The PANI emeraldine base shows relaxation in the range of - 90 to $65^{\circ} \mathrm{C}$, which is related to torsional motions of the aromatic ring in the chain ${ }^{27}$ or local motions of amine units ${ }^{28}$; a glass transition temperature of approximately $220^{\circ} \mathrm{C}^{29}$; and a transition at approximately $180^{\circ} \mathrm{C}$ that is related to crosslinking and decomposition of PANI. PAN has also been studied by DMTA, and in the regions of $80-100^{\circ} \mathrm{C}$ and $140-160^{\circ} \mathrm{C}$, we can see transitions related to chain van der Waals mobility and nitrile group motions ${ }^{30}$.

The aim of the present work is to investigate the effect of counterions and the content of PANI on nanocomposites based on PAN.

\section{Experimental}

Materials. Aniline (99\%, Sigma-Aldrich) was freshly distilled before polymerization under reduced pressure (7 mmHg). Ammonium persulfate (99\%, Sigma-Aldrich), hydrochloric acid (99\%, Sigma-Aldrich), acetic acid (99\%, Sigma-Aldrich), sulfuric acid (99\%, Sigma-Aldrich), methanol and potassium bromide (KBr, 99.9\%, Avantor Performance Materials Poland S.A.) were used as received. Water was purified by distillation. Dimethylformamide (DMF, 99.8\%) and polyacrylonitrile $(\mathrm{Mw}=150,000 \mathrm{~g} / \mathrm{mol}, 99 \%)$ were purchased from Sigma-Aldrich.

Synthesis of polyanilines. Polyanilines were synthesized via oxidative polymerization in water with ammonium persulfate as the oxidant in a solution of hydrochloric acid (A), acetic acid (B) or sulfuric acid (C). The amounts of reagents in each synthesis are presented in Table 1 . The reactions were conducted at room tem- 


\begin{tabular}{|l|l|}
\hline Parameter & Value \\
\hline Electrospinning process parameters & 3.5 \\
\hline Solution flow rate, $\mathrm{p}[\mathrm{mL} / \mathrm{h}]$ & 20 \\
\hline Potential difference between the electrodes, $\mathrm{U}[\mathrm{kV}]$ & 12.5 \\
\hline Distance between the electrodes, $\mathrm{d}[\mathrm{cm}]$ &
\end{tabular}

Table 2. Parameters for electrospinning PAN/PANI solution.

perature $\left(20^{\circ} \mathrm{C}\right)$. Representative synthesis was accomplished as follows. Aniline (9.313 g; $\left.0.1 \mathrm{~mol}\right)$ was poured into hydrochloric acid solution $(100.0 \mathrm{~g} ; 1.0 \mathrm{M})$ and stirred under ambient atmosphere (argon). A water solution $(100.0 \mathrm{~g})$ of ammonium persulfate $(28.523 \mathrm{~g} ; 0.125 \mathrm{~mol})$ was added to the reaction mixture and then stirred for $3 \mathrm{~h}$. The reaction mixture was filtered on filter paper, and dark-blue powder was collected after rinsing with a solution of acid as used for synthesis $(0.1 \mathrm{M})$, water and finally methanol. The powder was dried at $60^{\circ} \mathrm{C}$ in an oven under reduced pressure $(12 \mathrm{~h})$.

Electrospinning. Representative solutions for electrospinning were prepared as follows: polyacrylonitrile $\left(6.666^{\star} 10^{-2} \mathrm{mmol}\right)$ and polyaniline $(0.1 \mathrm{~g})$ were dissolved in dimethylformamide $(10.0 \mathrm{~g}, 99.8 \%$, SigmaAldrich). After $1 \mathrm{~h}$ of incubation, the solution was sonicated for $2 \mathrm{~h}$ prior to application to the pumping system of an electrospinning machine (FLOW-Nanotechnology Solutions Electrospinner 2.2.0-500). The final products were mixtures of DMF/PAN/PANI nanoparticles (sequentially (A), (B), (C)) at a concentration of 10\% by weight and 1 and 3\% concentrations of the PANI nanoparticles by weight. The process parameters are shown in Table 2.

Characterization. Thermogravimetric analysis (TGA) measurements were performed using a Pyris 1 (Perkin Elmer, USA) device. Experiments were carried out in a nitrogen stream $(20 \mathrm{~mL} / \mathrm{min})$ with a scanning rate of $10{ }^{\circ} \mathrm{C} / \mathrm{min}$ in the temperature range of $30-900{ }^{\circ} \mathrm{C}$. Differential scanning calorimetry (DSC) measurements were performed using a Q2000 calorimeter (TA Instruments, USA) in a nitrogen stream at a scanning rate of $20^{\circ} \mathrm{C} / \mathrm{min}$. Samples were analyzed in aluminum pans in the temperature range of $0-180^{\circ} \mathrm{C}$. Fourier transform infrared (FTIR) measurements were performed in the range of $4000-400 \mathrm{~cm}^{-1}$ with potassium bromide $(\mathrm{KBr})$ pressed pellets using a Spectrum One instrument (Perkin Elmer, USA). The samples were measured at room temperature, and pellets were prepared by mixing $10.0 \mathrm{mg}$ of polymer with $100.0 \mathrm{mg}$ of $\mathrm{KBr}$. The sample pellets were prepared by applying high pressure to a polymer sample with $\mathrm{KBr}$. The spectral resolution was $4 \mathrm{~cm}^{-1}$ in transmittance mode. UV-Vis spectra of the PANI $(4.0 \mathrm{mg})$ solutions in DMF $(100.0 \mathrm{~mL})$ were recorded using a Perkin-Elmer Lambda 40Bio spectrophotometer. The spectra were recorded from 250 to $900 \mathrm{~nm}$. Scanning electron microscopy (SEM) measurements were performed using a scanning electron microscope (Quanta 250 FEG, FEI Company, USA) operating with an acceleration voltage of $10 \mathrm{kV}$ under low vacuum (80 Pa). Electron micrographs were obtained from secondary electrons collected by a large-field detector (LFD). The samples were stuck to microscopic stubs by double-sided adhesive carbon tape. Micrograph analysis was carried out using ImageJ software (version: 1.52a, https://imagej.nih.gov/ij/download.html). Conductivity measurements were made using a two-point probe conductor using a Keithley 2400 multimeter. Sizes were determined with a Litesizer 500 (Anton Paar $\mathrm{GmbH}$, Austria) equipped with a $658 \mathrm{~nm}$ laser. The measurements were carried out under at $90^{\circ}$ in polystyrene cuvettes. Measurements were conducted 5 times at $25^{\circ} \mathrm{C}$ for $60 \mathrm{~s}$, with equilibration periods of $3 \mathrm{~min}$. Dynamic mechanical measurements were carried out on a DMTA Q800 (TA Instruments, USA) analyzer. DMTA allowed us to investigate the mechanical property behaviors related to Brownian motion of the polymer chains, such as variation in the mechanical modulus versus temperature. The mechanical dissipation factor, $\tan \delta$, as a measure of the deformational energy dissipated as heat during each cycle, is given by tan $\delta=\mathrm{E}^{\prime \prime} / \mathrm{E}^{\prime}$. The storage modulus, loss modulus and tangent $\delta$ of the samples were determined at $1 \mathrm{~Hz}$ and from -150 to $220^{\circ} \mathrm{C}$ at a heating rate of $3{ }^{\circ} \mathrm{C} / \mathrm{min}$. The sample dimensions were $15.0 \mathrm{~mm} \times 4.0 \mathrm{~mm}$ in compression mode. TGA, DSC, IR and UV-Vis as well as DMTA analysis were carried out using OriginPro 2019b (version: 9.6.5.169 x64, https://www.originlab.com/) software.

\section{Results and discussion}

The syntheses of all polyanilines in acidic medium at room temperature yielded dark-blue powders. A scheme of oxidative polymerization is presented in Fig. 1. The reaction proceeded under oxidative conditions with ammonium persulfate, as usual for polyanilines ${ }^{31}$. The final counterions in the polyanilines were supplied using hydrochloric acid (PANI A), acetic acid (PANI B) and sulfuric acid (PANI C). After filtration, the powders were dried in a $60^{\circ} \mathrm{C}$ oven under reduced pressure for $12 \mathrm{~h}$ and stored under an argon atmosphere. The reaction yields after filtration of powders were as follows: $92 \%$ for PANI A, 87\% for PANI B and 93\% for PANI C (Table 1).

The composite sheets that were the object of investigation were manufactured by applying electrospinning using the parameters listed in Table 2. Electrospinning conditions were selected on the basis of previous studies $^{5,32}$. The materials were diversified by the counterion used for PANI synthesis and the PANI content in the composites. The composites were produced with electrospinning due to the superiority of this process over cast or bulk methods of preparation. As shown in the literature, electrospinning improves the flexibility and plasticity of thin films and membranes. Electrospinning also improves the mechanical properties of films ${ }^{33}$. Cast films show a higher degree of crystallinity and lower Young's modulus values than electrospun films ${ }^{34}$. 
<smiles>CC(C)(C)c1ccc([N+]([O-])=C2C=CC(=[N+]([O-])c3ccc(Nc4ccc(Nc5ccccc5)cc4)cc3)C=C2)cc1</smiles>

Emeraldine salt

Figure 1. Oxidative polymerization of aniline using ammonium persulfate as an oxidant.

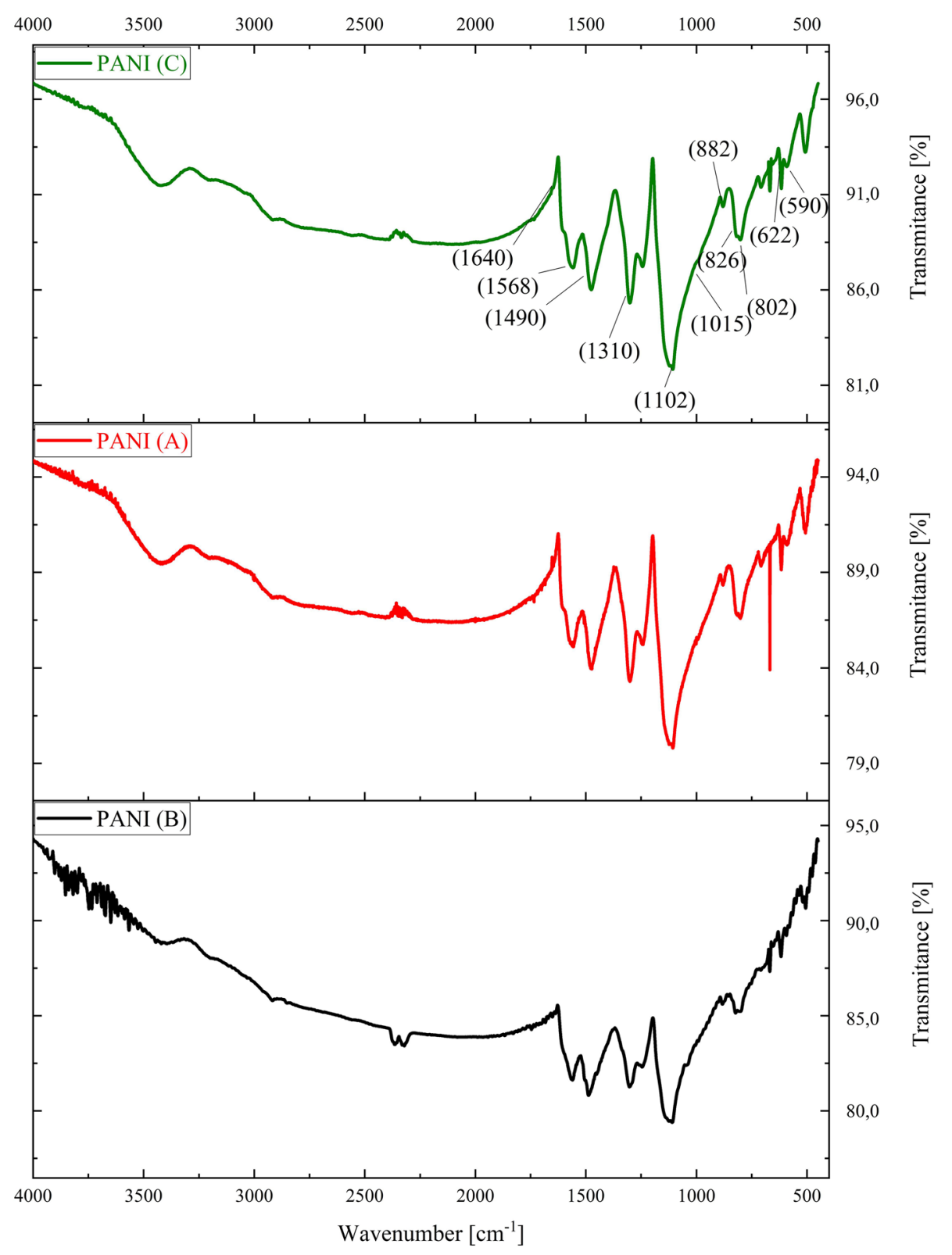

Figure 2. FTIR spectra of synthesized polyanilines (A, B, C).

The FTIR spectra (Fig. 2) of PANI A, PANI B, and PANI C reveal a N-H stretching band at $3400 \mathrm{~cm}^{-1}$. The quinonoid ring stretching vibrations are evidenced in the PANI A spectrum by the absorption band at $1568 \mathrm{~cm}^{-1}$, and the benzenoid ring stretching vibrations are at $1490 \mathrm{~cm}^{-1}$. The quinonoid ring stretching vibrations visible in the PANI B and PANI C spectra are represented by absorption bands at $1573 \mathrm{~cm}^{-1}$ and $1571 \mathrm{~cm}^{-1}$ and benzenoid ring stretching vibrations at $1497 \mathrm{~cm}^{-1}$ and $1494 \mathrm{~cm}^{-1}$, respectively. The shape of the $3400 \mathrm{~cm}^{-1}$ peak is the feature 

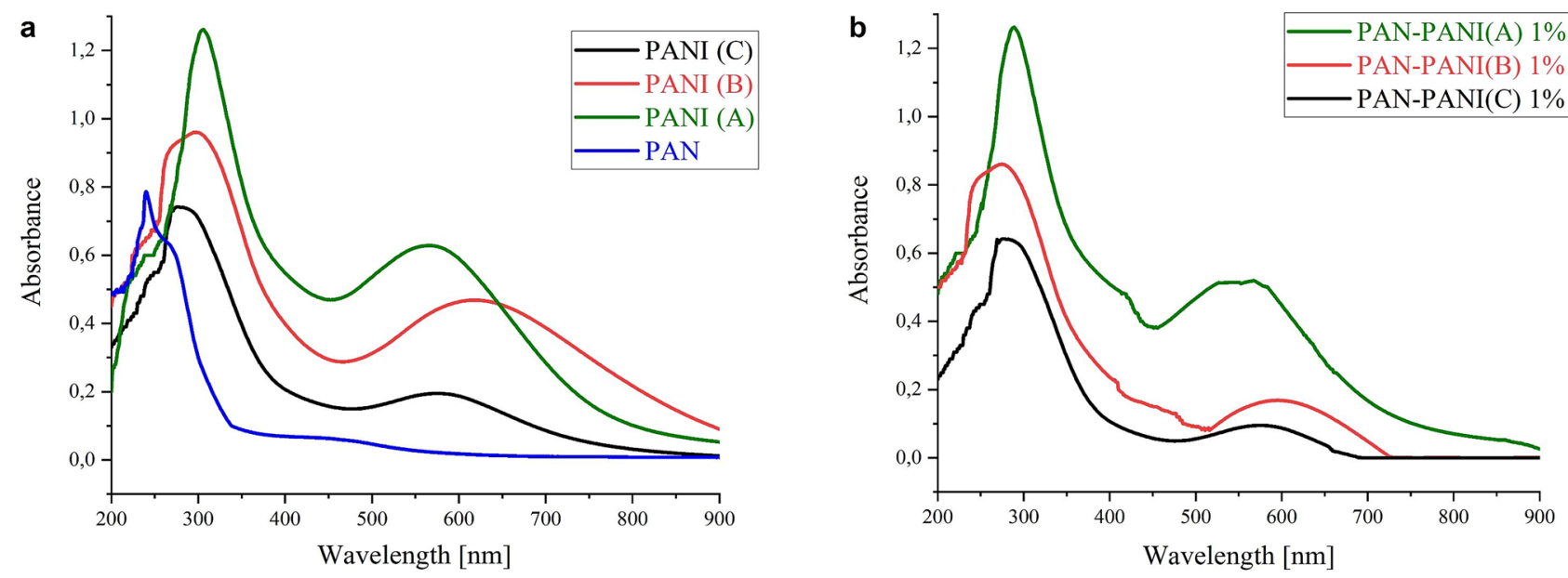

Figure 3. UV-Vis spectra of (a) synthesized polyanilines (A, B, C), polyacrylonitrile and (b) composites produced from polyanilines with polyacrylonitrile.

most dependent on the dopant because of the hydrogen bonding with amine groups. $\mathrm{C}-\mathrm{N}$ stretching bonds are visible at $1102 \mathrm{~cm}^{-1}, 1100 \mathrm{~cm}^{-1}$ and $1105 \mathrm{~cm}^{-1}$, and $\mathrm{C}=\mathrm{N}$ stretching bonds occur in the spectra at $1640 \mathrm{~cm}^{-1}$, $1650 \mathrm{~cm}^{-1}$ and $1642 \mathrm{~cm}^{-1}$ for PANI A, PANI B and PANI C, respectively. The absorption band at $1310 \mathrm{~cm}^{-1}$ in the PANI A spectrum corresponds to $\pi$-electron delocalization induced in the polymer by $\mathrm{C}-\mathrm{H}$ out-of-plane bending vibrations, which corresponds to a peak at $802 \mathrm{~cm}^{-1}$. In the PANI B spectrum, C-H out-of-plane bending was evidenced at $1307 \mathrm{~cm}^{-1}$ and $823 \mathrm{~cm}^{-1}$. The PANI C spectra exhibited C-H vibrations at $1305 \mathrm{~cm}^{-1}$ and $825 \mathrm{~cm}^{-1}$. The absorption at $1310-1305 \mathrm{~cm}^{-1}$ represents $\mathrm{C}-\mathrm{N}$ vibrations of secondary aromatic amines. The peaks at $1015 \mathrm{~cm}^{-1}$ and $826 \mathrm{~cm}^{-1}$ are related to the substituted ring of polyaniline, the latter being in the substitution region (900 to 650) $\mathrm{cm}^{-1}$. The spectra show a band located at $1150 \mathrm{~cm}^{-1}$, which has been assigned to the vibration mode of the $-\mathrm{NH}^{+}=$structure and is associated with the vibrations of the charged polymer quinonoid structure. This indicates the existence of positive charges on the polymer chain. The shoulder observed at $1045 \mathrm{~cm}^{-1}$ for the PANI C spectrum is attributable to symmetric $\mathrm{SO}_{3}$ stretching in the hydrogen sulfate counterion. In spectra of PANI B and PANI A, there is no such peak. The bands at $882 \mathrm{~cm}^{-1}$ and $875 \mathrm{~cm}^{-1}$ in the PANI A and PANI C spectra, respectively, were attributed to acidic counterions. The bands observed at 590 and $629 \mathrm{~cm}^{-1}$ in the spectra also correspond to sulfate counterions. The bands observed at 580 and $640 \mathrm{~cm}^{-1}$ in the spectra also correspond to chloride counterions. The results confirm the structure of polyaniline presented in the literature $\mathrm{e}^{27-30,35-39}$.

The UV-Vis absorption spectra of polyaniline (Fig. 3a) depend on the level of doping, extent of conjugation and solvent ${ }^{40}$. PANI spectra exhibit an absorption band at approximately $315-360 \mathrm{~nm}$ that is attributed to $\pi-\pi^{*}$ transitions in the benzenoid structure of the aromatic ring. The absorption band at approximately $580-630 \mathrm{~nm}$ corresponds to intramolecular transitions between the quinoid and benzenoid rings. The observed characteristic bands match those from the literature on $\mathrm{PANI}^{41-43}$. The UV-Vis spectra of the composites (Fig. 3b) exhibited absorption bands, and both bands shifted to the bathochromic region. The absorption bands at approximately 284-303 $\mathrm{nm}$ and 540-603 nm show lower intensities than those in the polyaniline spectra.

The thermal properties of the synthesized PANI and the thermomechanical properties of the manufactured composites were analyzed using TGA, DSC and DMTA measurements. Thermal stability was characterized by the temperatures at which 5\% (T5) or 10\% (T10) weight loss occurred, which was defined as the temperature at the beginning of thermal decomposition, and by the temperatures at the maximum rate of compound degradation (Tmax), which were determined from differential thermogravimetric analysis (DTA). The glass transition temperature $\left(T_{g}\right)$ was characterized using DSC and DMTA measurements. The results obtained from thermal measurements are collected in Table 3, whereas those from thermomechanical measurements are collected in Supplementary Material. The TGA and DMTA curves are depicted in Figs. 4 and 5.

The TGA thermograph of PAN shows a two-step degradation process. The first step of degradation indicates dehydrogenation of the polymer chain, and the second step indicates the depolymerization of the material (fragmentation of the macromolecule backbone), as reported previously ${ }^{44}$. Polyaniline shows three- or fourstep degradation depending on the counterion. The first weight loss, varying in the range of $43-69^{\circ} \mathrm{C}$, is caused by the evaporation of residual solvent (methanol) used for precipitate purification after synthesis ${ }^{25}$. The second and third degradation steps occur in the range of $222-312^{\circ} \mathrm{C}$ and are assigned to the degradation of polymer short fragments and the loss of dopant, respectively. PANI B exhibits a second step of degradation, which occurs between the second and third degradation steps for PANI A and PANI C. This phenomenon was explained by taking the radius of the dopants into consideration. The selected counterions have the following radii: $184 \mathrm{pm}$ for chloride (PANI A), $162 \mathrm{pm}$ for acetate (PANI B) and $258 \mathrm{pm}$ for sulfate (PANI C). PANI B was synthesized with the dopant of the smallest radius; therefore, such ions could form much stronger contact ion pairs with PANI than larger ions, such as those in PANI A and PANI C, whose equilibrium will be shifted toward separated ion pairs. Additionally, a smaller counterion could be better incorporated through the polymer backbone. The last degradation step, occurring above $579^{\circ} \mathrm{C}$, is triggered by thermal degradation of the PANI backbone and agrees with values presented elsewhere ${ }^{43}$. The maximum degradation step for the backbone occurs at the lowest 


\begin{tabular}{|c|c|c|c|c|c|c|c|}
\hline Sample & $\mathrm{T}_{5}\left({ }^{\circ} \mathrm{C}\right)$ & $\mathrm{T}_{10}\left({ }^{\circ} \mathrm{C}\right)$ & $\begin{array}{l}\text { Weight loss at } \\
300^{\circ} \mathrm{C}(\%)\end{array}$ & $\begin{array}{l}\text { Residue at } 900{ }^{\circ} \mathrm{C} \\
(\%)\end{array}$ & $\mathbf{T}_{\max }\left({ }^{\circ} \mathrm{C}\right)$ & $\mathrm{T}_{\mathrm{gDSC}}\left({ }^{\circ} \mathrm{C}\right)$ & $\mathrm{T}_{\text {gDMTA }}\left({ }^{\circ} \mathrm{C}\right)$ \\
\hline PANI A & 71 & 149 & 17.7 & 0.4 & $69 ; 239 ; 312 ; 585$ & 204 & - \\
\hline PANI B & 45 & 136 & 32.4 & 5.4 & $43 ; 281 ; 579$ & 205 & - \\
\hline PANI C & 90 & 229 & 24.5 & 1.3 & 63; 222; 297; 586 & 206 & - \\
\hline PAN & 321 & 325 & 0.8 & 37.1 & $325 ; 447$ & 94 & - \\
\hline PAN-PANI A (1\%) & 258 & 346 & 6.4 & 8.6 & $44 ; 122 ; 336 ; 451$ & 98 & 100 \\
\hline PAN-PANI A (3\%) & 268 & 331 & 5.6 & 34.6 & $32 ; 125 ; 368 ; 457$ & 103 & 107 \\
\hline PAN-PANI B (1\%) & 230 & 311 & 8.9 & 29.6 & $38 ; 125 ; 326 ; 439$ & 96 & 101 \\
\hline PAN-PANI B (3\%) & 251 & 330 & 6.5 & 37.5 & $44 ; 128 ; 338 ; 440$ & 98 & 109 \\
\hline PAN-PANI C ( $1 \%)$ & 244 & 293 & 11.5 & 12.6 & $\begin{array}{l}70 ; 124 ; 170 ; 303 ; \\
337 ; 664\end{array}$ & 95 & 99 \\
\hline PAN-PANI C (3\%) & 252 & 320 & 7.9 & 19.9 & $\begin{array}{l}50 ; 125 ; 305 ; 360 ; \\
772\end{array}$ & 98 & 106 \\
\hline
\end{tabular}

Table 3. Thermal properties of starting polymers and conductive composites. $\mathrm{T}_{5}$ and $\mathrm{T}_{10}$ represent the temperatures of 5 and $10 \%$ weight loss, $\mathrm{T}_{\max }$ is the temperature of the maximum decomposition rate as determined by DTA, $\mathrm{T}_{\mathrm{gDSC}}$ is the glass transition temperature by DSC, and $\mathrm{T}_{\mathrm{gDMTA}}$ is the glass transition temperature by DMTA.
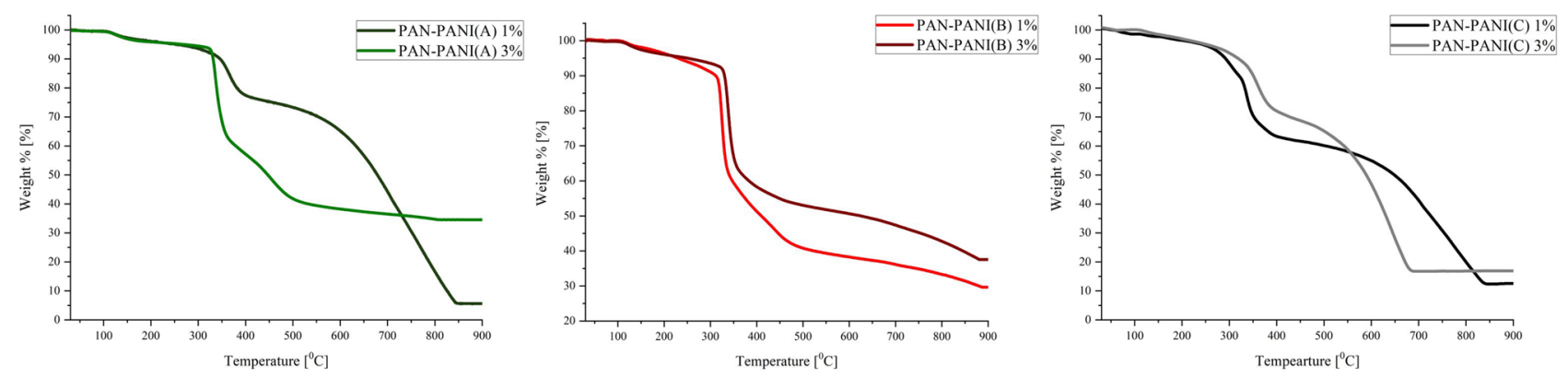

Figure 4. Thermogravimetric thermographs of the representative composites.

temperature for PANI B. Considering the $\mathrm{T}_{5}$ and $\mathrm{T}_{10}$ temperatures, PANI doped with sulfuric acid exhibited the best thermal stability.

The shapes of the TGA thermographs for composites of PAN-PANI A, B and C were similar to the thermographs of conductive polymers (Fig. 4). TGA thermographs indicated that the composites had better thermal stability than PANI but worse thermal stability than the PAN used in their creation. The thermal stability of the prepared composites was determined by the content of PANI in the bulk of the composite. The TGA results also prove that the PANI content impacts the thermal stability of the composite. Increasing the PANI concentration in the composite increased the thermal stability of all composites. The first weight loss of the composites is attributed to the evaporation of solvent used for composite purification. The second weight loss (between 122 and $128^{\circ} \mathrm{C}$ ) of the composites is attributed to the degradation of oligomers. The third weight loss of PAN-PANI $\mathrm{C}(1 \%)$ is assigned to evaporation of the solvent (dimethylformamide) used for composite preparation. Next, the degradation temperature of the composites varied in the range of $303-368^{\circ} \mathrm{C}$, which was attributed to dehydrogenation of the polymer backbone and loss of the PANI dopant. PAN-PANI C showed two peaks in this region, which are attributed to the sulfate having the largest radius of the counterions and are more evident for the composite. The last weight loss temperature of the composites, which appeared above $439^{\circ} \mathrm{C}$, is attributed to degradation of the polymer backbone, and it was related to the polyacrylonitrile degradation temperature. The general thermograph shape was dependent on the amount of polyaniline in the composites. The first and second weight losses for the composites diversified by PANI content were slightly different (Fig. 4). However, the third and fourth weight losses were more affected by the PANI content in the composite. The third weight loss for $1 \%$ and $3 \%$ PAN-PANI (A) occurred at $336^{\circ} \mathrm{C}$ and $368^{\circ} \mathrm{C}$, whereas for $1 \%$ PAN-PANI (B) and $3 \%$ PAN-PANI (B), it is visible at $326^{\circ} \mathrm{C}$ and $338^{\circ} \mathrm{C}$. For $1 \%$ and $3 \%$ PAN-PANI (C), weight losses first occurred at $303^{\circ} \mathrm{C}$ and $305^{\circ} \mathrm{C}$ and then at $337^{\circ} \mathrm{C}$ and $360^{\circ} \mathrm{C}$, respectively. The temperature shifts were $22^{\circ} \mathrm{C}$ for PAN-PANI (A), $12^{\circ} \mathrm{C}$ for PAN-PANI (B) and $2{ }^{\circ} \mathrm{C}$ and $23^{\circ} \mathrm{C}$ for PAN-PANI (C). Such evidence indicates better thermal stability for composites with $3 \%$ PANI than for those with $1 \%$ PANI content. The composite manufactured with PANI C exhibited the largest difference between the $1 \%$ and $3 \%$ additions. The final residue after thermal analysis was in the range of $12-38 \%$ of the initial weight and was, in all cases, approximately $8 \%$ higher for composites with $3 \%$ PANI content than for other composites. The degradation temperature of polymers increased with increasing PANI content. Composite PAN-PANI (A) exhibited a degradation peak at $451^{\circ} \mathrm{C}$ for $1 \%$ PANI content and $457^{\circ} \mathrm{C}$ for $3 \%$ PANI content. The degradation for PAN-PANI (B) started at $439^{\circ} \mathrm{C}$ and $440{ }^{\circ} \mathrm{C}$ for $1 \%$ and $3 \%$ PANI, respectively. The PAN-PANI (C) composite exhibited a degradation temperature of $664^{\circ} \mathrm{C}$ for $1 \%$ PANI 

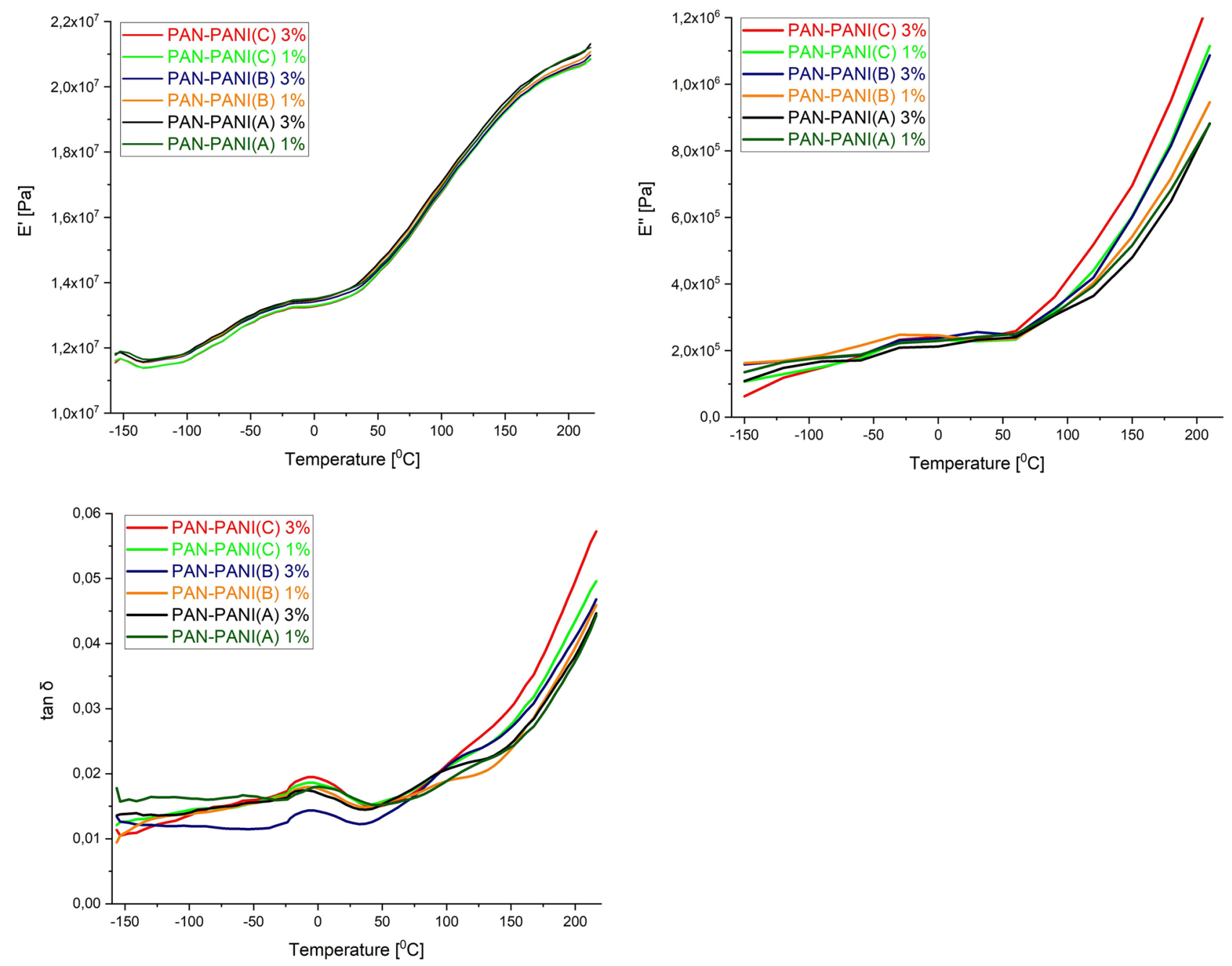

Figure 5. Loss modulus ( $\left.\mathrm{E}^{\prime \prime}\right)$, storage modulus $\left(\mathrm{E}^{\prime}\right)$ and tangent delta $(\tan \delta)$ of PAN-PANI composites.

content and $772{ }^{\circ} \mathrm{C}$ for $3 \%$ PANI content. The composite prepared with PANI doped with sulfuric acid exhibited the most stable thermograph.

The glass transition temperatures of polyanilines shown in Table 2 range from 204 to $206^{\circ} \mathrm{C}$, which are typical $\mathrm{T}_{\mathrm{g}}$ values for polyaniline $\mathrm{e}^{10}$. The $\mathrm{T}_{\mathrm{g}}$ for PAN is $94^{\circ} \mathrm{C}$, which is similar to values in the literature $\mathrm{f}^{45,46}$. The glass transition temperatures for composites determined via the DSC and DMTA methods were in the range of $95-112^{\circ} \mathrm{C}$. DSC thermographs of all samples (PANI, PAN and composites) showed that during the first heating scan there was an endothermic peak in the range of $40-60^{\circ} \mathrm{C}$ due to the elimination of moisture, which was also observed in the TGA thermographs. The second endothermic peak visible in the DSC thermographs of the composites appeared in the range of $95-103{ }^{\circ} \mathrm{C}$ and was related to the glass transition temperatures of the materials. The DMTA $T_{g}$ values were slightly higher than those obtained with the DSC method. Differences between the two methods were common, as the exact position of Tg depends on the frequency used in DMTA, whereas in DSC, it depends on the heating rate used ${ }^{45}$. In this study, the DSC heating rate was $20^{\circ} \mathrm{C} / \mathrm{min}$, whereas the DMTA heating rate was $3{ }^{\circ} \mathrm{C} / \mathrm{min}$. In general, the $\mathrm{T}_{\mathrm{g}}$ occurs at higher temperatures for composites with $3 \%$ PANI than for composites with $1 \%$ PANI. For example, the PAN-PANI (A) $1 \% \mathrm{~T}_{\mathrm{g}}$ obtained by DSC was $98{ }^{\circ} \mathrm{C}$, while that obtained by DMTA was $100^{\circ} \mathrm{C}$. The PAN-PANI (A) $3 \% \mathrm{~T}_{\mathrm{g}}$ obtained by DSC was $103^{\circ} \mathrm{C}$, while that obtained by DMTA was $107^{\circ} \mathrm{C}$. The difference between $\mathrm{T}_{\mathrm{g}}$ for PAN-PANI (A) $1 \%$ obtained with the DSC method was $5^{\circ} \mathrm{C}$, and that obtained by the DMTA method was $7^{\circ} \mathrm{C}$. The PAN-PANI (B) $1 \% \mathrm{~T}_{\mathrm{g}}$ values were $96^{\circ} \mathrm{C}$ (DSC) and $101^{\circ} \mathrm{C}$ (DMTA), and the PAN-PANI (B) $3 \% \mathrm{~T}_{\mathrm{g}}$ values were $98^{\circ} \mathrm{C}$ (DSC) and $109^{\circ} \mathrm{C}$ (DMTA). The differences in $\mathrm{T}_{\mathrm{g}}$ between PAN-PANI (B) composites with $1 \%$ and $3 \%$ PANI content were $2{ }^{\circ} \mathrm{C}$ for the DSC method and $8{ }^{\circ} \mathrm{C}$ for the DMTA method. The PAN-PANI (C) $1 \% \mathrm{~T}_{\mathrm{g}}$ values were $95^{\circ} \mathrm{C}$ (DSC) and $99^{\circ} \mathrm{C}$ (DMTA), and the PAN-PANI (C) $3 \% \mathrm{~T}_{\mathrm{g}}$ values were $98^{\circ} \mathrm{C}$ (DSC) and $106^{\circ} \mathrm{C}$ (DMTA). The differences in $\mathrm{T}_{\mathrm{g}}$ values for this composite with $1 \%$ and $3 \%$ PANI content were $3{ }^{\circ} \mathrm{C}$ for the DSC method and $7{ }^{\circ} \mathrm{C}$ for the DMTA method.

The mechanical characterization of composites was performed in compression mode in the temperature range of -150 to $220^{\circ} \mathrm{C}$ at a heating rate of $3{ }^{\circ} \mathrm{C} / \mathrm{min}$ and frequency of $1 \mathrm{~Hz}$. The dimensions of the samples were $15.0 \times 4.0 \mathrm{~mm}$. Figure 5 shows the variations in the loss modulus, storage modulus and tangent $\delta$ of the materials. Table 4 shows the relationship of the storage modulus of the composites versus the temperature. Two peaks were 


\begin{tabular}{|l|l|l|l|}
\hline Sample & Conductivity $(\mathbf{S} / \mathbf{c m})$ & Particle size in water $(\mathbf{n m})$ & Yarn size $(\mathbf{n m})$ \\
\hline PANI A & 8.7 & 49 & - \\
\hline PANI B & 6.5 & 46 & - \\
\hline PANI C & 10.8 & 57 & - \\
\hline PAN-PANI A (1\%) & $1.2^{\star} 10^{-2}$ & - & 192 \\
\hline PAN-PANI A (3\%) & $1.2^{\star} 10^{-2}$ & - & 221 \\
\hline PAN-PANI B (1\%) & $0.7^{\star} 10^{-2}$ & - & 181 \\
\hline PAN-PANI B (3\%) & $0.9^{\star} 10^{-2}$ & - & 211 \\
\hline PAN-PANI C (1\%) & $2.5^{\star} 10^{-2}$ & - & 224 \\
\hline PAN-PANI C (3\%) & $2.8^{\star} 10^{-2}$ & - & 234 \\
\hline
\end{tabular}

Table 4. Electric conductivity and fiber size of polymers and conductive composites.

clearly seen for the storage modulus: one in the -100 to $-40{ }^{\circ} \mathrm{C}$ region $(\beta)$ and another in the 20 to $70{ }^{\circ} \mathrm{C}$ region $\left(\beta^{\prime}\right)$. When the temperature rose above $\mathrm{Tg}$, the storage modulus increased until $220^{\circ} \mathrm{C}$, which can be explained by physical and chemical crosslinking of the polyaniline chain ${ }^{28,29,47-52}$. The $\beta$ transition between -80 and $-60^{\circ} \mathrm{C}$ is related to local motions of amine groups in polyaniline, and the $\beta^{\prime}$ transition is related to benzene ring motions and rotations of amine groups, also as reported in the literature in the range of -20 to $20^{\circ} \mathrm{C}\left(\beta^{\prime}\right)$. According to the literature, polyacrylonitrile shows its most intense transition at approximately $100{ }^{\circ} \mathrm{C}$ and a second minor transition at $150^{\circ} \mathrm{C}$. The lower transition temperature is characteristic of the paracrystalline phase transition of the polymer, and the higher corresponds to the amorphous phase transition (glass) ${ }^{53}$. Three curve inflections can be clearly seen in the loss modulus: the first is in the $-60{ }^{\circ} \mathrm{C}$ region, the second above $-30{ }^{\circ} \mathrm{C}$, and the third above $60^{\circ} \mathrm{C}$. The peak starting to increase at $60^{\circ} \mathrm{C}$ represents the glass transition of composites, in agreement with the $\tan \delta$ results. The tangent $\delta$ curve indicates two glass transition temperatures, one at approximately $-10^{\circ} \mathrm{C}$ and one that is related to DSC and DMTA measurements at $105^{\circ} \mathrm{C}$.

$\beta$ relaxation was observed for the PANI emeraldine base at $-80^{\circ} \mathrm{C}(1 \mathrm{~Hz})^{28,48}$. This relaxation is attributed to the torsional motions of the aromatic rings in the polymer chain, i.e., the torsions of benzenoid and quinoid cycles present in the structure of the chain. The $\beta$ relaxation of polyaniline films in NMP $(5 \mathrm{~Hz})$ was also observed, in the region of -80 to $-60^{\circ} \mathrm{C}^{49}$. These studies have shown that $\beta$ relaxation is linked to the residual content of water in the films due to water molecules that are hydrogen bonded to the polymeric chain. Studies have noted $\beta^{\prime}$ relaxation in polyaniline films in the region of -20 to $2^{\circ} \mathrm{C}^{49}$. These studies explained the transition as being due to the motion of molecules hydrogen bonded to NMP.

The storage modulus value increases with increasing PANI in the composite, which can be attributed to the increased crosslinking of polyaniline with increasing temperature. The same trend is visible for the loss modulus and $\tan \delta$. The crosslinking restricts the mobility of the polymer molecules and, consequently, composite molecular mobility.

The results of conductivity measurements are given in Table 4. The measurements were repeated 10 times on each sample. The conductivity of the prepared composites was dependent on the PANI content and on the dopant used in the synthesis. The polymer prepared with acetic acid (PANI B) showed the lowest conductivity of all polyanilines, similar to the composite made from PANI B exhibiting the lowest conductivity of the composites. The highest conductivity was exhibited by the composite based on polyaniline doped with sulfuric acid (PANI C). In general, with more PANI, the composite material exhibits slightly better conductivity except for the material with PANI A. The literature suggests that such a conductivity value is promising for further investigations, that is, for this material's use in electrode preparation for DSSCs ${ }^{46}$. The particle size of polyanilines was measured with dynamic light scattering in a water suspension at $25^{\circ} \mathrm{C}$. The polyaniline synthesized with sulfuric acid exhibited the largest particle size, whereas acetic acid doping revealed the smallest particle size for PANI.

The SEM images presented in Fig. 6 show the surfaces of the polymer composites. The fiber diameter was averaged for 100 fibers from at least 5 micrographs. The results are shown in Table 4. As shown in Fig. 6, the composites have a three-dimensional network structure composed of randomly oriented polymer fibers. The yarn size is in the range of 192-234 nm and depends on the polyaniline content; thus, composites with $3 \%$ polyaniline content are slightly larger. For example, the PAN-PANI A (1\%) composite exhibits a yarn size of $192 \mathrm{~nm}$, and the same composite with a $3 \%$ PANI content exhibits a yarn size of $29 \mathrm{~nm}$. In the case of the PAN-PANI B composite, the difference between yarn sizes of the $1 \%$ and $3 \%$ PANI contents was $30 \mathrm{~nm}$, and that for the PAN-PANI C composite was $10 \mathrm{~nm}$. The yarn size was related to the conductivity of the composites; the higher the conductivity of the material was, the greater the yarn size. Increasing the polyaniline content in the composite increased the formation of small agglomerates on fiber surfaces, which can be explained by the increasing conductivity of the composites. The yarn sizes were in agreement with the particle sizes determined by DLS in water. A dependence of particle size on yarn size was clearly visible. The largest particle size corresponded to the largest composite yarn. The PANI C polymer exhibited a particle size of $57 \mathrm{~nm}$, and the composites showed sizes of $224 \mathrm{~nm}$ and $234 \mathrm{~nm}$ for the composite with 1\% PANI and the composite with 3\% PANI, respectively. PANI A was smallest PANI (49 nm), and PAN-PANI A (1\%: $192 \mathrm{~nm}, 3 \%: 221 \mathrm{~nm})$ was the smallest composite. 


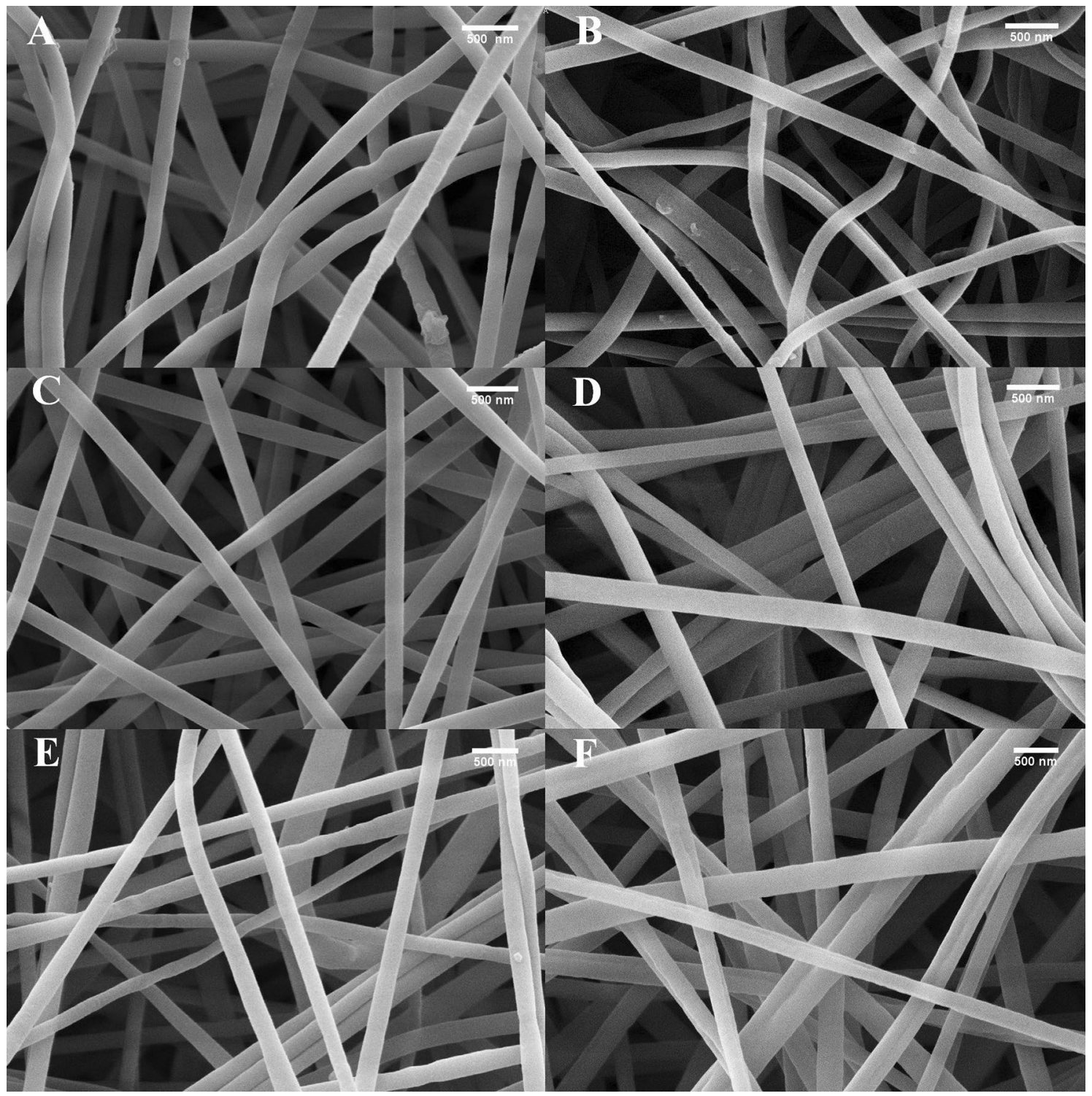

Figure 6. SEM photographs of polyaniline-polyacrylonitrile composites: (A) PAN-PANI A (1\%), (B) PANPANI A (3\%), (C) PAN-PANI B (1\%), (D) PAN-PANI B (3\%), (E) PAN-PANI C (1\%), (F) PAN-PANI C (3\%).

\section{Conclusions}

Herein, the counterion impact on the thermal and mechanical properties of electrospun composite sheets was discussed. The explored materials were diversified by varying the counterion used for PANI synthesis and the PANI content in composite. The best thermal stability as represented by $\mathrm{T}_{5}$ was exhibited for $3 \%$ PANI obtained with hydrochloric acid; nonetheless, all samples were stable in the range of $230-268^{\circ} \mathrm{C}$. The thermal stability and glass transition temperature increased with increasing PANI content in the composite. The storage modulus similarly increased with increasing PANI content. Such variability can indeed be connected to the yarn size increasing with the content of PANI. The thermal stability of the composites predisposes them for use in the construction of organic electronics, among other applications. The impact of the PANI content on the electroconductivity of composites is less significant than the influence of the dopant type on the material properties. The highest conductivity $\left(2.8^{*} 10^{-2} \mathrm{~S} / \mathrm{cm}\right)$ was exhibited by composites based on polyaniline doped with sulfuric acid. It should be stressed that such composites seem to be promising for further study, i.e., for testing them as electrodes in dye-sensitized solar cells due to their costs of production being lower than that of platinum counter electrodes. Research involving modification of the electrospinning process and increasing PANI content will be developed in our further investigations.

Received: 1 September 2020; Accepted: 11 March 2021

Published online: 05 April 2021 


\section{References}

1. Sun, G., Sun, L., Xie, H. \& Liu, J. Electrospinning of nanofibres for energy applications. Nanomaterials 6, 129-159 (2016).

2. Nagata, S., Atkinson, G. M., Pestov, D., Tepper, G. C. \& Mcleskey, J. T. Jr. Electrospun polymer-fibre solar cell. Adv. Mater. Sci. Eng. 2013, 1-6 (2013).

3. Pierini, F., Lanzi, M., Nakielski, P. \& Kowalewski, T. A. Electrospun polyaniline-based composite nanofibres: tuning the electrical conductivity by tailoring the structure of thiol-protected metal nanoparticles. J. Nanomater. 2017, 1-10 (2017).

4. Pierini, F. et al. Single-material organic solar cells based on electrospun fullerene-grafted polythiophene nanofibres. Macromolecules 50, 4972-4981 (2017).

5. Raeesi, F., Nouri, M. \& Haghi, A. K. Electrospinning of polyaniline-polyacrylonitrile blend nanofibers. e-Polymers 114, 1-13. https://doi.org/10.1515/epoly.2009.9.1.1350 (2009).

6. Zhang, Z. et al. Electrospinning and microwave absorption of polyaniline/polyacrylonitrile/multiwalled carbon nanotubes nanocomposite fibres. Fibres Polym. 15, 2290-2296 (2014).

7. Kizildag, N., Ucar, N., Demirsoy, N., Eren, O., Karacan, I. et al. Conducting polyacrylonitrile (PAN)/polyaniline (PANI) composite nanofibres produced by electrospinning method. In Fibre Society's Spring 2014 Conference, Vol. 1, pp. 1-3 (2014).

8. Zhang, J. et al. Nanostructured polyaniline counter electrode for dye-sensitised solar cells: fabrication and investigation of its electrochemical formation mechanism. Electrochem. Acta 55, 3664-3668 (2010).

9. Li, Z. et al. Facile electropolymerized-PANI as counter electrode for low cost dye-sensitized solar cell. Electrochem. Commun. 11, $1768-1771$ (2009).

10. Ameen, S. et al. Plasma-enhanced polymerized aniline/TiO ${ }_{2}$ dye-sensitized solar cells. J. Alloys Compd. 487, 382-386 (2009).

11. Shahid, M. U. et al. Few-layer graphene supported polyaniline (PANI) film as a transparent counter electrode for dye-sensitized solar cells. Diam. Relat. Mater. 94, 242-251 (2019).

12. Stejskal, J., Sapurina, I., Prokes, J. \& Zemek, J. In situ polymerized polyaniline films. Synth. Met. 105, 195-202 (1999).

13. MacDiarmid, A. G. et al. "Polyaniline": interconversion of metallic and insulating forms. Mol. Cryst. Liq. Cryst. 121, 173-180 (1985).

14. Gospodinova, N. \& Terlemezyan, L. Conducting polymers prepared by oxidative polymerization: polyaniline. Prog. Polym. Sci. 23, 1443-1484 (1998).

15. Virji, S., Huang, J., Weiller, B. H. \& Kaner, R. B. Polyaniline nanofibre gas sensors: examination of response mechanisms. Nano Lett. 4, 491-496 (2004).

16. Ha, J., Cho, J. \& Jang, J. Fabrcation of water-dispersible polyaniline-poly(4-styrenesulfonate) nanoparticles for inkjet-printed chemical-sensor applications. Adv. Mater. 19, 1772-1775 (2007).

17. Li, X., Li, X. \& Wang, G. Fibrillar polyaniline/diatomite composite synthesized by one-step in situ polymerization method. Appl. Surf. Sci. 249, 266-270 (2005).

18. Qiu, H., Wan, M., Matthews, B. \& Dai, L. Conducting polyaniline nanotubes by template-free polymerization. Macromolecules 34, 675-677 (2001).

19. Wan, M. X. Some issues related to polyaniline micro-/nanostructures. Macromol. Rapid Commun. 30, $963-975$ (2009).

20. Stejskal, J., Sapurina, I., Trchová, M. \& Konyushenko, E. N. Oxidation of aniline: polyaniline granules, nanotubes, and oligoaniline microspheres. Macromolecules 41, 3530-3536 (2008).

21. Sunghun, C., Kwon, O. S., You, A. A. \& Jang, J. Shape-controlled polyaniline chemiresistors for high-performance DMMP sensors: effect of morphologies and charge-transport properties. J. Mater. Chem. A 1, 5679-5688 (2013).

22. Tang, Q., Wu, J., Sun, X., Li, Q. \& Lin, J. Shape and size control of oriented polyaniline microstructure by a self-assembly method. Langmuir 25, 5253-5257 (2009).

23. Qavamnia, S. S. \& Nasouri, K. Conductive polyacrylonitrile/polyaniline nanofibres prepared by electrospinning process. Polym. Sci. Ser. A 57, 343-349 (2015).

24. Bertea, A., Manea, L. R. \& Hristian, L. Associated polymers, solvents and doping agents to make polyaniline electrospinnable. IOP Conf. Ser. Mater. Sci. Eng. 209, 012073 (2017).

25. Karbownik, I., Rac-Rumijowska, O., Fiedot-Toboła, M., Rybicki, T. \& Teterycz, H. The preparation and characterization of polyacrylonitrile-polyaniline (PAN/PANI) fibres. Materials 12, 664-684 (2019).

26. Andreatta, A., Cao, Y., Chiang, J. C., Heeger, A. J. \& Smith, P. Electrically-conductive fibres of polyaniline spun from solutions in concentrated sulfuric acid. Synth. Met. 26, 383-389 (1988).

27. Chen, S. A. \& Lee, H. T,: Polyaniline plasticized with 1-methyl-2-pyrrolidone: structure and doping behaviour. Macromolecules 26, 3254-3261 (1993).

28. Milton, A. J. \& Monkman, A. P. Thermal analysis of polyaniline free standing films. Synth. Met. 57, 3571-3575 (1993).

29. Ding, L., Wang, X. \& Gregory, R. V. Thermal properties of chemically synthesized polyaniline (EB) powder. Synth. Met. 104, 73-78 (1999).

30. Stejskal, J., Prokes, J. \& Trchova, M. Reprotonation of polyaniline: a route to various conducting polymer materials. React. Funct. Polym. 68, 1355-1361 (2008).

31. Tang, S. J. et al. Polymerization of aniline under various concentrations of APS and HCl. Polym. J. 43, 667-675 (2011).

32. Baştürk, E., Çakmakçi, E., Madakba, S. \& Kahraman, M. Surface and proton conductivity properties of electrospun poly(vinyl butyral)/polyaniline nanofibers. Adv. Polym. Technol. 37, 1774-1781 (2018).

33. Kajal, G. et al. Electrospinning over solvent casting: tuning of mechanical properties of membranes. Sci. Rep. 8, 1-9 (2018).

34. Ahmed, F. et al. Preparation and characterizations of polyaniline (PANI)/ZnO nanocomposites film using solution casting method. Thin Solid Films 519, 8375-8378 (2011).

35. Trchová, M. \& Stejskal, J. Polyaniline: the infrared spectroscopy of conducting polymer nanotubes. Pure Appl. Chem. 83, 1803-1817 (2011).

36. Ping, Z. J. In situ FTIR-attenuated total reflection spectroscopic investigations on the base-acid transitions of polyaniline. Base-acid transition in the emeraldine form of polyaniline. Chem. Soc. Faraday Trans. 92, 3063-3067 (1996)

37. Kang, E. T., Neoh, K. G. \& Tan, K. L. Polyaniline: a polymer with many interesting intrinsic redox states. Prog. Polym. Sci. 23, 277-324 (1998).

38. Trchová, M. et al. Evolution of polyaniline nanotubes: the oxidation of aniline in water. J. Phys. Chem. B. 110, 9461-9468 (2006).

39. Socrates, G. Infrared and Raman Characteristic Group Frequencies. 107-113, 122-123, 157-167, 176-177, 220-222 (Wiley, 2001).

40. Swaruparani, H., Basavaraja, S., Basavaraja, C., Huh, D. S. \& Venkataraman, A. A new approach to soluble polyaniline and its copolymers with toluidines. J. Appl. Polym. Sci. 117, 1350-1360 (2010).

41. Amarnath, C. A., Kim, J., Kim, K., Choi, J. \& Sohn, D. Nanoflakes to nanorods and nanospheres transition of selenious doped polyaniline. Polymer 49, 432-437 (2008).

42. Neelgund, G. M. \& Oki, A. A facile method for synthesis of polyaniline nanospheres and effect of doping on their electrical conductivity. Polym. Int. 60, 1291-1295 (2011).

43. Yang, Y., Ding, Y., Chen, G. \& Li, C. Synthesis of conducting polyaniline using novel anionic Gemini surfactant as micellar stabilizer. Eur. Polym. J. 43, 3337-3343 (2007). 
44. Al-Ahmed, A., Mohammad, F. \& Rahman, M. Preparation, characterization, thermooxidative degradation, and stability of polyaniline/polyacrylonitrile composites in terms of direct-current electrical conductivity retention. Appl. Polym. Sci. 99, 437-448 (2006).

45. Howard, W. H. The glass temperatures of polyacrylonitrile and acrylonitrile-vinyl acetate copolymers. J. Appl. Polym. Sci. 5, 303-307 (1961).

46. Beevers, R. B. Dependence of the glass transition temperature of polyacrylonitrile on molecular weight. J. Polym. Sci. Part A 2, 5257-5265 (1964).

47. Kenyon, A. S. \& Rayford, M. C. J. Mechanical relaxation processes in polyacrylonitrile polymers and copolymers. J. Appl. Polym. Sci. 23, 717-725 (1979).

48. Milton, A. J. \& Monkman, A. P. A comparative study of polyaniline films using thermal analyses and IR spectroscopy. J. Phys. D Appl. Phys. 26, 1468-1474 (1993).

49. Rodrigues, P. C., De Souza, G. P., Da Motta Neto, J. \& Akcelrud, L. Thermal treatment and dynamic mechanical thermal properties of polyaniline. Polymer 43, 5493-5499 (2002).

50. Wei, Y. et al. Thermal transitions and mechanical properties of films of chemically prepared polyaniline. Polymer 33, 314-322 (1992).

51. Chen, S. A. \& Lee, H. T. Polyaniline plasticized with 1-methyl-2-pyrrolidone: structure and doping behaviour. Macromolecules 26, 3254-3261 (1993).

52. Han, M. G., Lee, Y. J., Byun, S. W. \& Im, S. S. Physical properties and thermal transition of polyaniline film. Synth. Met. 124, 337-343 (2001).

53. Bikiaris, D., Prinos, J., Botev, M., Betchev, C. \& Panayiotou, C. Blends of polymers with similar glass transition temperatures: a DMTA and DSC study. J. Appl. Polym. Sci. 93, 726-735 (2004).

\section{Author contributions}

K.B.- the experimental investigation, synthesis of polymers, spectroscopy and thermogravimetric measurements. W.M.-preparation of polymer materials by electrospinning. T.T.-conception of electrospinning investigation, microscopy investigation. H.J.- differential scanning calorimetry measurements. E.S-B.-conductivity investigation in aspect of photovoltaic usefulness, verification of thermogravimetric and differential scanning calorimetry investigation. M.L.-conception of experiments, coordination of investigation, validation of results and microscopy investigation.

\section{Funding}

This study was funded by the National Science Centre, Project Number 2016/23/B/ST8/02045.

\section{Competing interests}

The authors declare no competing interests.

\section{Additional information}

Supplementary Information The online version contains supplementary material available at https://doi.org/ 10.1038/s41598-021-86950-4.

Correspondence and requests for materials should be addressed to M.L.

Reprints and permissions information is available at www.nature.com/reprints.

Publisher's note Springer Nature remains neutral with regard to jurisdictional claims in published maps and institutional affiliations.

(c) (i) Open Access This article is licensed under a Creative Commons Attribution 4.0 International License, which permits use, sharing, adaptation, distribution and reproduction in any medium or format, as long as you give appropriate credit to the original author(s) and the source, provide a link to the Creative Commons licence, and indicate if changes were made. The images or other third party material in this article are included in the article's Creative Commons licence, unless indicated otherwise in a credit line to the material. If material is not included in the article's Creative Commons licence and your intended use is not permitted by statutory regulation or exceeds the permitted use, you will need to obtain permission directly from the copyright holder. To view a copy of this licence, visit http://creativecommons.org/licenses/by/4.0/.

(C) The Author(s) 2021 